\title{
ESTUDO DO PROCESSO DE FABRICAÇÃO DE BRIQUETES COMPOSTOS DE CARVÃO VEGETAL E CARVÃO FÓSSIL*
}

\section{Resumo}

Lina Maria Varón Cardona ${ }^{1}$

Cesar Yuji Narita²

Marcelo Breda Mourão ${ }^{3}$

Cyro Takano 4

A utilização de briquetes de misturas de carvão fóssil e biomassa em substituição ao coque como agente redutor pode contribuir para a diminuição das emissões de $\mathrm{CO}_{2}$ à atmosfera no processo de fabricação de ferro através da substituição de parte do carvão fóssil por carvão vegetal. O objetivo deste artigo é identificar quais são as principais variáveis que influenciam a produção de briquetes de alta qualidade a partir de misturas de carvão fóssil e carvão vegetal. Os briquetes foram fabricados em matriz cilíndrica, compactados em prensa hidráulica e tratados termicamente em forno vertical aquecido com resistência elétrica sob atmosfera de nitrogênio. Foi investigada a influência da composição da mistura, da taxa de aquecimento e do tamanho de partícula do carvão fóssil. Os briquetes com composição na faixa de $10 \%$ a $15 \%$ de carvão vegetal moído e peneirado em partículas menores que 325 mesh apresentaram maior resistência à compressão. Foi observado que o efeito do envelhecimento do carvão influencia na qualidade do briquete, pois diminui sua resistência à compressão; as dimensões finais dos briquetes após tratamento térmico diminuíram quando a velocidade de aquecimento é menor; ao se aplicar maior velocidade de aquecimento os briquetes apresentam inchamento.

Palavras-chave: Biocoque; Briquetes, Siderurgia.

\section{STUDY OF MANUFACTURING PROCESS OF BRIQUETTES COMPOUNDS CHARCOAL AND FOSSIL COAL}

\begin{abstract}
The concerns in questions related to the environmental impact in the steelmaking industries caused mainly on the gas emissions such as the dioxide carbon are due to its raw material such as the coal, a fossil and non renewable resource. The purpose of this paper is to replace from $10 \%$ to $50 \%$ of the coal used in cokemaking by mixing it with a renewable source (wood charcoal). The powder (- 325 mesh) from both raw materials (coal and wood charcoal) were mixed in order to obtain a briquette that was then heat treated at $1,100^{\circ} \mathrm{C}$ to obtain the biocoke. It was found that biocoke with different amounts of wood charcoal present features enabling it to be used in some ore reduction processes.
\end{abstract}

Keywords: Biocoke; Coal-charcoal briquette; Ironmaking.

1 Engenheira Mecânica, Doutoranda, Departamento de Engenharia Metalúrgica e de Materiais da Escola Politécnica da Universidade de São Paulo, São Paulo, SP, Brasil.

2 Engenheiro Metalurgista, Mestrando, Departamento de Engenharia Metalúrgica e de Materiais da Escola Politécnica da Universidade de São Paulo, São Paulo, SP, Brasil.

3 Professor Associado, Departamento de Engenharia Metalúrgica e de Materiais da Escola Politécnica da Universidade de São Paulo, São Paulo, SP, Brasil.

4 Professor Associado, Departamento de Engenharia Metalúrgica e de Materiais da Escola Politécnica da Universidade de São Paulo, São Paulo, SP, Brasil.

\footnotetext{
* Contribuição técnica ao $44^{\circ}$ Seminário de Redução de Minério de Ferro e Matérias-primas, 15ํ Simpósio Brasileiro de Minério de Ferro e $2^{\circ}$ Simpósio Brasileiro de Aglomeração de Minério de Ferro, 15 a 18 de setembro de 2014, Belo Horizonte, MG, Brasil.
} 


\section{INTRODUÇÃO}

Existem diferentes razões para utilizar parcialmente o carvão vegetal na produção de coque metalúrgico como agente redutor na produção de ferro. A primeira é que com a substituição parcial de carvão fóssil por carvão vegetal se reduz a geração global de $\mathrm{CO}_{2}$ na indústria siderúrgica [1]. Atualmente, a indústria siderúrgica está substituindo parcialmente o coque metalúrgico por biomassa procedente de diferentes fontes como bagaço de cana, casca de coco, madeira entre outras [2]. 0 uso de misturas de carvão fóssil e carvão vegetal na fabricação de briquetes também é uma opção para a concentração de energia, principalmente porque parte do carvão vegetal fabricado é inutilizado devido à degradação granulométrica ocorrida durante o transporte e manuseio, desde a região carvoeira até os consumidores.

Atualmente, 96\% da indústria siderúrgica no mundo utiliza o carvão fóssil na forma de coque no processo de produção de ferro [2]. Isto ocorre devido às suas características de produtividade, resistência mecânica e menor consumo específico de carbono, o que permite a produção de grandes volumes de gusa comparado coma quantidade produzida nos mini altos fornos a carvão vegetal. Apesar destas qualidades, a indústria siderúrgica tem sido considerada uma grande emissora de $\mathrm{CO}_{2}$ [2], sendo que $75 \%$ das emissões de $\mathrm{CO}_{2}$ provenientes das siderúrgicas são gerados no processo de redução do minério de ferro com o carvão fóssil [3]. É sabido que o uso de carvão vegetal apresenta um balanço zero de emissão de $\mathrm{CO}_{2}$ [4], uma vez que em florestas plantadas todo $\mathrm{O}^{\mathrm{CO}_{2}}$ gerado é consumido no crescimento de novas arvores. Portanto, uma possível solução para diminuição do $\mathrm{CO}_{2}$ gerado na fabricação do ferrogusa é a utilização de misturas de carvão fóssil e carvão vegetal na produção de coque.

A literatura não contém muita informação sobre adição de biomassa em carvão fóssil. Um dos primeiros estudos realizados no Brasil relacionados com a briquetagem de misturas de carvão fóssil e carvão vegetal "biocoque" foi feito por Broschet al. [5]. Em sua pesquisa foram testadas misturas de carvão vegetal e fóssil utilizando melaço como aglomerante com o objetivo de desenvolver técnicas experimentais para aproveitar finos de carvão vegetal em aglomerados, especialmente briquetes.

A adição de carvão vegetal em blendas de carvões fósseis utilizada na fabricação de coque foi estudada por MacPhee et. al. [6]. Um dos principais resultados desta pesquisa foi que a adição de carvão vegetal em até $10 \%$ na mistura produz um aumento no índice de reatividade do coque (CRI) e uma diminuição no índice de reatividade após reação de $\mathrm{CO}_{2}$ (CSR). Uma das conclusões de seu estudo foi que a introdução de carvão vegetal finamente moído em uma mistura de carvões coqueificáveis produz coque de baixa qualidade. Isto pode ser o resultado da alta concentração de cálcio, que, assim como outros constituintes da cinza no carvão, produz coque mais reativo ao $\mathrm{CO}_{2}$. Outra conclusão foi que com maior tamanho das partículas de carvão fóssil se obtém melhor qualidade do coque.

Das et al. [7] misturaram biomassa com carvão não coqueificável de alto conteúdo de cinzas para produzir coque. Concluíram que o carvão não coqueificável misturado com uma adequada biomassa poderia produzir um coque de boa resistência à compressão para ser utilizado na indústria siderúrgica quando misturado com uma adequada biomassa.

Quando adicionadas em misturas de carvão fóssil, partículas finas de carvão vegetal atuam como material inerte e são totalmente incorporadas dentro da estrutura do

* Contribuição técnica ao 44 Seminário de Redução de Minério de Ferro e Matérias-primas, $15^{\circ}$ Simpósio Brasileiro de Minério de Ferro e 2ำ Simpósio Brasileiro de Aglomeração de Minério de Ferro, 15 a 18 de setembro de 2014, Belo Horizonte, MG, Brasil. 
coque. Para a resistência a frio, Maranha et al. [8] mostra que os inertes atuam como nucleantes e propagadores de fissuras durante a solidificação e contração do coque ou semi-coque, tornando a estrutura do coque menos compacta e menos resistente à degradação. Para a resistência a quente os inertes fazem o biocoque mais reativo ao $\mathrm{CO}_{2}$. Em contrapartida, ter poucos inertes também pode ter impactos negativos sobre a resistência à compressão, pois não há material inerte suficiente para ajudar a engrossar as paredes das porosidades do coque.

Mourão et al. [9] substituíram entre $10 \%$ a $50 \%$ de carvão coqueificável com carvão vegetal, briquetando em prensa hidráulica. As amostras foram tratadas termicamente e depois foram testadas em sua resistência à compressão após tratamento.

Os autores observaram que os briquetes apresentam propriedades dependentes da quantidade de carvão na mistura. Entretanto, não encontraram uma relação clara entre a quantidade de carvão na mistura e a reatividade dos briquetes. Mourão et al. também concluíram que após reação com $\mathrm{CO}_{2}$, a resistência à compressão diminuiu. Além disso, briquetes contendo $20 \%$ em massa de carvão vegetal apresentaram os maiores valores de resistência antes edepois da reação, apresentando também alta reatividade.

O objetivo deste artigo é identificar quais são as principais variáveis que influenciam na produção de briquetes de alta qualidade a partir de misturas de carvão fóssil coqueificável e carvão vegetal.

\section{MATERIAIS E MÉTODOS}

A madeira utilizada para o carvão vegetal foi fornecida pela estação experimental da Escola Superior de Agricultura Luiz de Queiroz (ESALQ), denominada por "Eucalyptus Saligna" de sete anos de idade. A madeira foi carbonizada a $400^{\circ} \mathrm{C}$ durante 3 horas.

Foram utilizados dois carvões fósseis coqueificáveis com teor médio de voláteis e com fluidez média. O primeiro, chamado de Blue Creek, foi doado pela siderúrgica USIMINAS - Unidade Cubatão. O segundo carvão, chamado de Chipanga e procedente de Moçambique, foi doado pela mineradora Vale. Na Tabela 1 são apresentadas as análises imediatas e na Tabela 2 Erro! Fonte de referência não encontrada.a composição das cinzas dos dois carvões.

Tabela 1. Análise imediata do carvão

\begin{tabular}{cccc}
\hline & $\begin{array}{c}\text { Blue Creek } \\
{[\%]}\end{array}$ & Chipanga [\%] & $\begin{array}{c}\text { Carvão } \\
\text { vegetal [\%] }\end{array}$ \\
\hline Matéria Volátil & 28,1 & 23,76 & 23,01 \\
\hline Cinzas & 7,2 & 10,56 & 2,38 \\
\hline Carbono Fixo & 64,7 & 65,58 & 79,85 \\
\hline
\end{tabular}

\footnotetext{
* Contribuição técnica ao $44^{\circ}$ Seminário de Redução de Minério de Ferro e Matérias-primas, 15ํ Simpósio Brasileiro de Minério de Ferro e $2^{\circ}$ Simpósio Brasileiro de Aglomeração de Minério de Ferro, 15 a 18 de setembro de 2014, Belo Horizonte, MG, Brasil.
} 




Os carvões foram moídos para menos de 325 mesh. Foram preparadas misturas de carvão vegetal e carvões Blue Creek e Chipanga com diferentes proporções. As misturas foram compactadas em prensa hidráulica a 13,8 MPa. Os briquetes foram fabricados em matriz cilíndrica de $11,5 \mathrm{~mm}$ de diâmetro e tratados termicamente em forno vertical aquecido com resistência elétrica em atmosfera de nitrogênio. 0 tratamento térmico consistiu em colocar a amostra dentro do forno a temperatura ambiente, e elevar a temperatura a uma taxa constante até $500^{\circ} \mathrm{C}$ em 3 horas, com a amostra permanecendo neste patamar por 1 hora. Após isto, a temperatura é elevada até $1.100^{\circ} \mathrm{C}$ em 3 horas, mantendo-se este patamar por mais 1 hora. No total, o tratamento térmico durou 8 horas. As amostras foram resfriadas lentamente dentro do forno desligado em atmosfera de nitrogênio. Os briquetes foram caracterizados antes e depois do tratamento.

Testes de resistência à compressão em máquina de ensaios universal foram feitos com os briquetes após tratamento térmico. Os briquetes eram acomodados na máquina universal, de modo que ficassem de pé, ou seja, com uma de suas faces circulares virada para baixo e a outra para cima, mantendo o mesmo sentido da carga de compressão da briquetagem. Os testes foram realizados com velocidade de deslocamento de $3 \mathrm{~mm} / \mathrm{min}$ até o briquete quebrar.

\section{RESULTADOS E DISCUSSÃO}

Os resultados de densidade aparente antes e depois do tratamento térmico até $1.100^{\circ} \mathrm{C}$ são apresentados na Figura 1. Antes do tratamento, como esperado, 0 aumento da porcentagem de carvão vegetal causa diminuição linear da densidade aparente dos briquetes devido à menor densidade do carvão vegetal comparado com o carvão fóssil. Após tratamento térmico, observa-se que a densidade aumenta quando é usado entre 0 a $20 \%$ de carvão vegetal, pois o carvão vegetal age como inerte, auxiliando a saída dos gases e diminuindo a porosidade produzida pelo carvão fóssil durante a fluidificação.

\footnotetext{
* Contribuição técnica ao $44^{\circ}$ Seminário de Redução de Minério de Ferro e Matérias-primas, 15ํ Simpósio Brasileiro de Minério de Ferro e $2^{\circ}$ Simpósio Brasileiro de Aglomeração de Minério de Ferro, 15 a 18 de setembro de 2014, Belo Horizonte, MG, Brasil.
} 
De acordo com a Figura 1, a influência do carvão vegetal é mais marcante em quantidades maiores que $7 \%$ de carvão vegetal, pois se nota que nestes casos a densidade final é maior que a densidade inicial. Para quantidades menores que $7 \%$, os briquetes apresentam inchamento, mostrado pela densidade final menor que a inicial.

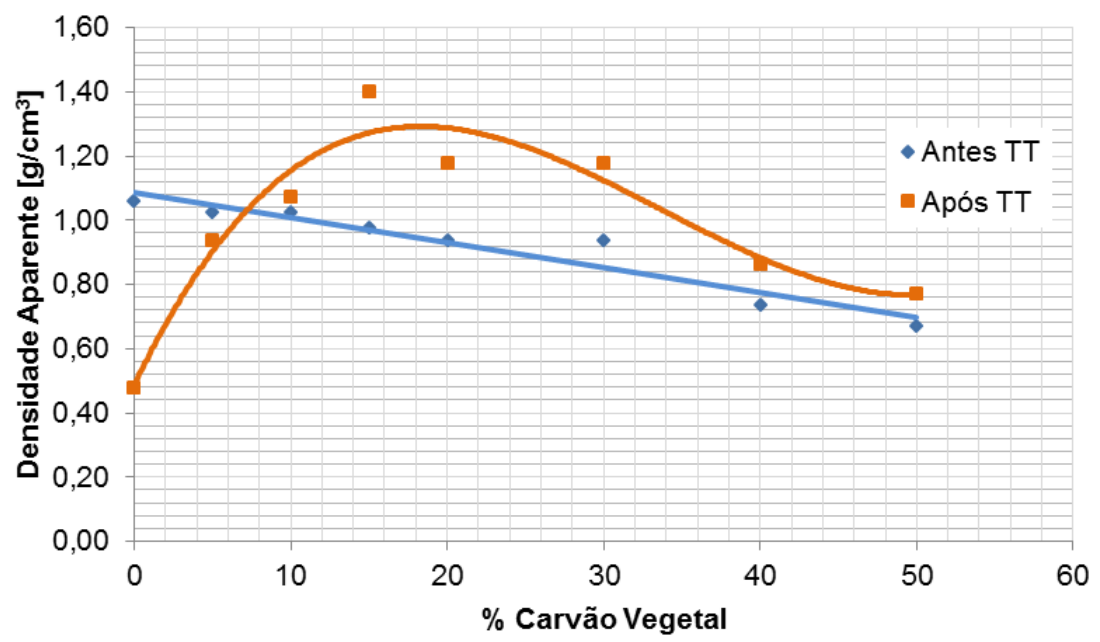

Figura 1. Densidade aparente da mistura de carvão Chipanga e carvão vegetal, antes e depois de tratamento térmico a $1.100^{\circ} \mathrm{C}$.

O mesmo comportamento obtido com o carvão Chipanga a respeito da densidade foi obtido para o carvão Blue Creek. Na Tabela 3 são mostrados os resultados para os dois diferentes carvões.

Tabela 3. Densidade Aparente $[\mathrm{g} / \mathrm{cm} 3]$

\begin{tabular}{ccccc}
\hline \multirow{2}{*}{$\%$ CV } & \multicolumn{2}{c}{ Blue Creek } & \multicolumn{2}{c}{ Chipanga } \\
\cline { 2 - 5 } & Antes TT & Depois TT & Antes TT & Depois TT \\
\hline 0 & 1,03 & 1,93 & 1,06 & 0,48 \\
\hline 5 & 0,97 & 0,44 & 1,03 & 0,94 \\
\hline 10 & 0,96 & 1,33 & 1,03 & 1,07 \\
\hline 15 & 0,96 & 0,00 & 0,98 & 1,40 \\
\hline 20 & 0,96 & 0,00 & 0,94 & 1,18 \\
\hline 30 & 0,68 & 0,00 & 0,94 & 1,18 \\
\hline 40 & 0,68 & 0,77 & 0,74 & 0,86 \\
\hline 50 & 0,60 & 0,68 & 0,67 & 0,77 \\
\hline
\end{tabular}

Analisou-se a influência do aumento da porcentagem de carvão vegetal na resistência à compressão dos briquetes. Na Figura 2 é observado que as misturas com carvão Chipanga apresentaram maior resistência à compressão do que as misturas feitas com carvão Blue Creek.

Embora haja diferença na resistência à compressão entre as misturas com os dois carvões, é observado que o aumento da porcentagem de carvão vegetal implica em aumento da resistência à compressão até $15 \%$ de carvão vegetal. Este comportamento coincide com o máximo de densidade aparente apresentado na Figura 1. A partir deste ponto a resistência à compressão baixa rapidamente.

* Contribuição técnica ao 44 Seminário de Redução de Minério de Ferro e Matérias-primas, 15오 Simpósio Brasileiro de Minério de Ferro e 2ํ Simpósio Brasileiro de Aglomeração de Minério de Ferro, 15 a 18 de setembro de 2014, Belo Horizonte, MG, Brasil. 


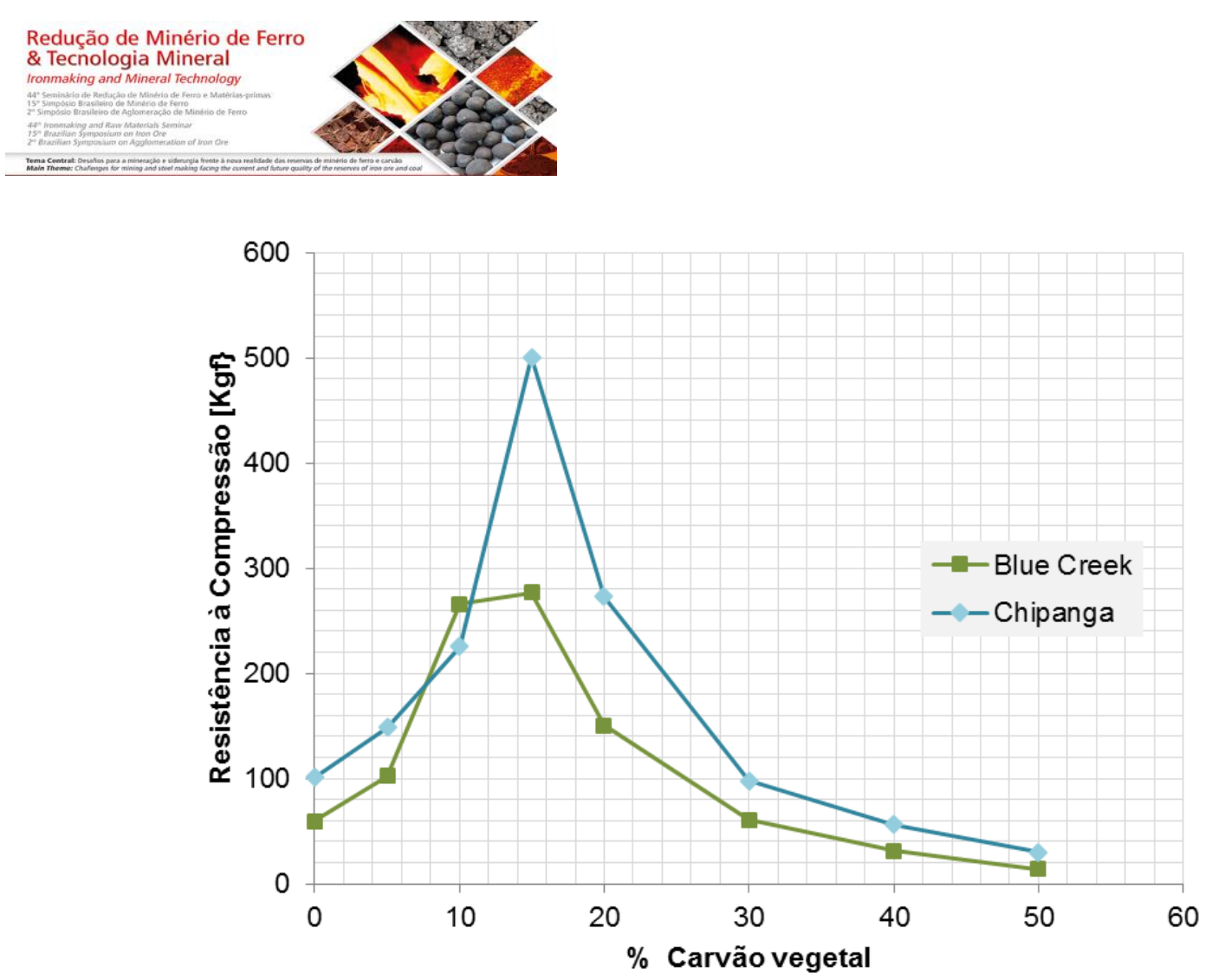

Figura 2. Resistência à compressão em função da porcentagem de carvão vegetal de briquetes de dois diferentes tipos de carvão fóssil depois de tratamento térmico a $1.100^{\circ} \mathrm{C}$.

Ao se manter a utilização de carvão Chipanga e a $15 \%$ de carvão vegetal no briquete, foi alterada a temperatura máxima do tratamento térmico em duas condições: $500^{\circ} \mathrm{C}$ e $1.100^{\circ} \mathrm{C}$. A $500^{\circ} \mathrm{C}$, a resistência à compressão obtida foi $257 \mathrm{kgf}$; a $1.100^{\circ} \mathrm{C}, 500 \mathrm{kgf}$. Desta forma, nota-se aumento da resistência à compressão com o aumento da temperatura máxima do tratamento térmico. Com as amostras submetidas a $500^{\circ} \mathrm{C}$, esperava-se que a maior parte dos voláteis presentes no carvão já tivesse saído e a fase de fluidificação na amostra tivesse terminado. Neste sentido, não se esperava grandes diferenças na resistência mecânica. No entanto, ainda devem acontecer reações após essa temperatura que aumentam a resistência do biocoque.

A Tabela 4 mostra uma comparação dos resultados de resistência à compressão com os dois carvões. Nota-se que os briquetes preparados com Blue Creek e tratados termicamente a $1.100^{\circ} \mathrm{C}$ possuem menor resistência à compressão que briquetes baseados no carvão Chipanga tratados termicamente a $500^{\circ} \mathrm{C}$. Desta forma, é possível afirmar que o carvão Chipanga foi mais benéfico para a resistência mecânica dos briquetes misturados com carvão vegetal.

Tabela 4. Dados comparativos da resistência à compressão do carvão Chipanga e Blue Creek misturados com $15 \%$ de carvão vegetal a diferentes temperaturas máximas.

\begin{tabular}{ccc} 
Carvão & $\mathrm{T} \max \left[{ }^{\circ} \mathrm{C}\right]$ & $\mathrm{R}$. Compressão $\left[\mathrm{Kgf} / \mathrm{cm}^{2}\right]$ \\
\hline Chipanga & 500 & 257 \\
\hline Chipanga & 1.100 & 500 \\
\hline Blue Creek & 1.100 & 218 \\
\hline
\end{tabular}

* Contribuição técnica ao $44^{\circ}$ Seminário de Redução de Minério de Ferro e Matérias-primas, 15ㅇ Simpósio Brasileiro de Minério de Ferro e 2o Simpósio Brasileiro de Aglomeração de Minério de Ferro, 15 a 18 de setembro de 2014, Belo Horizonte, MG, Brasil. 


\section{CONCLUSÃO}

- A densidade após tratamento térmico aumenta quando a mistura contém até $20 \%$ de carvão vegetal. Este fenômeno foi observado com o uso dos dois tipos de carvão fóssil;

- Até $15 \%$ de carvão vegetal na mistura, verifica-se um aumento da resistência à compressão do briquete. Isto coincide com o máximo de densidade aparente observado. Após o máximo, há rápida diminuição da resistência mecânica;

- Com o aumento da temperatura máxima de tratamento térmico foi observado aumento da resistência à compressão do briquete.

\section{Agradecimentos}

Os autores gostariam de agradecer à Coordenação de Aperfeiçoamento de Pessoal de Nível Superior (CAPES) pelo apoio financeiro, à siderúrgica Usiminas - Unidade Cubatão e à Vale pelas amostras cedidas e análises e à Lorena da Costa Nascimento, pesquisadora do Centro de Tecnologia de Ferrosos da Vale, pelas discussões e contribuições técnicas.

\section{REFERÊNCIAS}

1 Cavaliero CKN, Jannuzzi GM. A importância do segmento siderúrgico nas emissões de CO2 Nacional e do Estado de São Paulo. In: XX Seminário de Balanços Energéticos Globais e Utilidades; 1998. São Paulo: Associação Brasileira de Metalurgia e Materiais; 1998.

2 IPCC Special Report on Carbon Dioxide Capture and Storage, Prepared by Working Group III of the International Panel on Climate Change. Metz D, Davidson O, Coninck H, Loos M, Meyer L (eds.), Cambridge University Press; 2005.

3 Worldsteel Association. Steel's contribution to a low carbon future. Março 2013 [acesso em jul. 2014]. Disponível em:

http://www.worldsteel.org/dms/internetDocumentList/downloads/publications/Climatechange-position-paperA4/document/Climate\%20change\% 20position\%20pape r\%20A4. pdf.

4 CGEE - Centro de Gestão e Estudos Energéticos. Incremento do Carvão Vegetal Renovável na Siderurgia Brasileira: Relatório Final. Brasília; 2010.

5 Brosch CD, Furuno JK. Aproveitamento dos finos de carvão vegetal. Divisão de metalurgia do Instituto de Pesquisas Tecnológicas de São Paulo. In: Congresso Anual da ABM 12; 1968; Vitória, Brasil. São Paulo: ABM; 1968.

6 Macphee JA, Gransden JF, Giroux L, Price JT. Fuelprocessing Technology. 2009;90:16-20.

7 Das S, Sharma S, Choudhury R. Non-coking coal to coke: use of biomass based blending material. Energy. 2002;27:405-414.

8 Maranha SP, Machado JGMS, Nascimento LC, Peddolla PK, Scholes O. Mozambique coal - the uncommon petrographic quality and its consequences on the coke Strength. In: 43ํㅗㄴ Seminário de redução de minério de ferro e Matérias Primas, 12Simpósio Brasileiro de aglomeração e minério de ferro; 1 a 4 set. 2013; Belo Horizonte, Brasil. São Paulo: ABM; 2013.

9 Mourao MB, Narita CY, Tanaka MT, Takano C. Technical viability of biocoke from mixtures coal-wood charcoal for use in ironmaking. Energy Technology 2013: Carbon Dioxide Management and Other Technologies. 248 p. March 2013.

\footnotetext{
* Contribuição técnica ao $44^{\circ}$ Seminário de Redução de Minério de Ferro e Matérias-primas, 15ํ Simpósio Brasileiro de Minério de Ferro e $2^{\circ}$ Simpósio Brasileiro de Aglomeração de Minério de Ferro, 15 a 18 de setembro de 2014, Belo Horizonte, MG, Brasil.
} 